\title{
PROBLEMATIZAÇÕES CONTEMPORÂNEAS SOBRE A ESCALARIDADE: FORMA, NATUREZA E ORGANIZAÇÃO DAS ESCALAS GEOGRÁFICAS
}

\author{
Matheus da Silveira Grandi ${ }^{1}$ \\ Universidade do Estado do Rio de Janeiro
}

Enviado em 29 abr. 2019 | Aceito em 14 fev. 2020

Resumo: O "problema da escala" emerge na Geografia no momento em que a necessidade de organizar as unidades espaciais possíveis de serem identificadas é ressaltada como uma preocupação metodológica, sendo assim explicitado e tratado no âmbito acadêmico da Geografia sobretudo a partir da década de 1950. A difusão de certos referenciais teórico-políticos nas pesquisas sócio-espaciais ocidentais possibilitou que a questão escalar fosse, nos anos seguintes, observada desde abordagens para as quais dividir e organizar o espaço não era uma questão meramente metodológica, mas também epistemológica, política e, portanto, diretamente ligada à prática e à ação social. Mas a proliferação de trabalhos sobre as escalas geográficas não ocorreu homogeneamente nos diferentes ambientes linguísticos da literatura especializada. No caso anglófono, por exemplo, foi a partir do final da década de 1980 que isso aconteceu. 0 objetivo deste artigo é caracterizar os principais eixos do debate sobre as escalas geográficas que se desenrolou entre aproximadamente a última década do século XX e a primeira década do século XXI nas pesquisas realizadas no ambiente da Geografia anglófona de forma a incrementar a pluralidade de questões que fertilizam as compreensões sobre a escala geográfica.

Palavras-chave: Escala geográfica; História do Pensamento Geográfico; Geografia anglófona.

\section{CONTEMPORARY TOPICS ON SCALARITY: FORM, NATURE, AND ORGANISATION OF GEOGRAPHICAL SCALES}

Abstract: The "scale problem" emerges in Geography at the moment in which the need to organize the possibly identifiable spatial units is highlighted as a methodological concern. Thus, it became explicit and treated in this academic field, specially from the 1950s onward. In the following years the diffusion of other theoretical-political references in Western socio-spatial research allowed the scalar issue to be observed from approaches for which the act of divide and organize the space was not merely a methodological issue, but also an epistemological and political one -and, therefore, scale was recognized as directly linked to the practice and social action. But the proliferation of works on geographical scales did not occur homogeneously in the different linguistic environments of the specialized literature. In the Anglophone case, for example, it was from the end of the 1980s that this happened. The aim of this article is to characterize the main axes of the debate on geographical scales that took place between approximately the last decade of the twentieth century and the first decade of the twenty-first century in the research carried out in the environment of Anglophone Geography in order to increase the plurality of issues that fertilize the understandings on geographical scale.

Keywords: Geographical scale; History of Geographical Thought; Anglophone geography.

\section{CUESTIONES CONTEMPORÁNEAS SOBRE LA ESCALARIDAD: FORMA, NATURALEZA Y ORGANIZACIÓN DE LAS ESCALAS GEOGRÁFICAS}

Resumen: El "problema de la escala" surge en Geografía en el momento en que se pone de manifiesto la necesidad de organizar las unidades espaciales identificables como una preocupación metodológica. Así, el tema se vuelve explícito y tratado en este ámbito académico principalmente a partir de la década de 1950. La difusión de ciertas referencias teórico-políticas en las investigaciones socio-espaciales ocidentales permitió que la cuestión escalar fuera, en los años siguientes, observada desde enfoques para los que dividir y organizar el espacio no era una cuestión meramente metodológica, sino también epistemológica y política -y, por lo tanto, directamente vinculada a la práctica y a la acción social. Pero la proliferación de trabajos sobre escalas geográficas no se produjo de forma homogénea en los distintos ámbitos lingüísticos de la literatura especializada. En el caso anglófono, por ejemplo, eso ocurrió a partir de finales de los años ochenta. El objetivo de este artículo es caracterizar los principales ejes del debate sobre las escalas geográficas que tuvo lugar aproximadamente entre la última década del siglo XX y la primera del siglo XXI en las investigaciones realizadas en el entorno de la Geografía anglófona con el fin de aumentar la pluralidad de cuestiones que alimentan las reflexiones sobre la escala geográfica.

Palabras clave: Escala geográfica; Historia del Pensamiento Geográfico; Geografía anglófona.

1. Doutor em Geografia. Professor do Programa de Pós-Graduação em Geografia da Faculdade de Formação de Professores da Universidade do Estado do Rio de Janeiro. ORCID: https://orcid.org/0000-0001-8342-6792 . E-mail: mtsgrandi@gmail.com 


\section{Introdução}

A dimensão escalar reúne preocupações com a divisão e a organização das partes do espaço em totalidades espaciais, oferecendo formas de organizar as informações com o intuito de compreender os fenômenos e poder agir sobre eles. Apesar de a escalaridade - entendida como a relação entre a identificação de unidades espaciais e sua organização em totalidades - permear os estudos sobre a dimensão espacial desde a antiguidade, foi no final do século XIX e início do século XX que a preocupação em definir as unidades espaciais ideais para tais estudos ganhou destaque. 0 desenvolvimento da estatística e o imperativo da definição de prioridades para guiar ações estatais e empresariais no final da primeira metade do século $X X$, no entanto, trouxeram à tona problemas relativos à comparabilidade dos dados nas pesquisas espaciais. O "problema da escala" emerge nesse momento em que a necessidade de organizar as unidades espaciais possíveis de serem identificadas é ressaltada como uma preocupação metodológica, sendo assim explicitado e tratado no âmbito acadêmico da Geografia sobretudo a partir da década de 1950 (BAHIANA, 1986; MOORE, 2008; HEROD, 2011; GRANDI, 2016).

Em resposta à ênfase em metodologias quantitativas de abordagem positivista predominantes a partir de então - e apesar de sua diversidade interna -, as décadas seguintes viram outras perspectivas a respeito da dimensão espacial serem ressaltadas. A difusão de certos referenciais teórico-políticos nas pesquisas sócio-espaciais possibilitou que a questão escalar fosse observada desde abordagens para as quais dividir e organizar o espaço não era uma questão meramente metodológica, mas também epistemológica, política e, portanto, diretamente ligada à prática e à ação social. A proliferação de trabalhos sobre as escalas geográficas não ocorreu, porém, homogeneamente nos diferentes ambientes linguísticos da literatura especializada. No caso anglófono, onde tal debate teve maior vulto, foi a partir do final da década de 1980 que isso aconteceu, processo que ficou conhecido como de "abertura" do conceito de escala na Geografia.

O objetivo destas páginas é caracterizar os principais eixos do debate sobre as escalas geográficas que se desenrolou entre aproximadamente a última década do século XX e a primeira década do século XXI nas pesquisas realizadas no ambiente da Geografia anglófona de forma a contribuir para a compreensão da questão da escala geográfica. Para isso, as próximas páginas contarão com uma indicação sucinta das principais referências apontadas como pioneiras nas críticas à abordagem exclusivamente metodológica de inspirações positivistas do problema das escalas geográficas que emerge a partir da década de 1950. Em seguida serão apresentados os eixos que estruturam o debate sobre o conceito ocorrido no ambiente anglófono no período indicado. Por fim, apontarei caminhos para pesquisas futuras ligadas à reflexão sobre a trajetória brasileira desse tema.

\section{Subjetividade e a politização da escala}

O existencialismo e a fenomenologia foram duas das tradições filosóficas que ofereceram bases férteis às críticas ao cientificismo positivista predominante na geografia a partir da década de 1950. Sob essas influências a geografia passou a conviver, sobretudo a partir do final da década de 1960, com novas referências que estimulavam pesquisas sobre o papel de aspectos subjetivos (a percepção, o comportamento, os afetos, os sentimentos etc.) na espacialidade humana. Tais interesses passaram a ser incorporados às investigações também como percepção de um mundo que apresentava não só diferentes níveis de realidade, mas também níveis perceptivos distintos, incentivando novos olhares sobre a escalaridade. Marcaram tais pesquisas as reflexões de autores 
como Yi-Fu Tuan (1980, 1983), ao apresentar o lugar em diversas escalas que vão da poltrona à Terra; Thomas Saarinen (1969), ao revisar a literatura dos estudos da percepção organizando-a por diferentes escalas de investigação (a "geografia do aposento", o espaço arquitetônico, a escala do bairro, a cidade - a nível regional, nacional e mundial); Antoine Bailly e Brian Greer-Wooten (1983), com a retomada da bibliografia francófona; e Armand Frémont, com seu livro "Região: Espaço vivido", fundamental na articulação da tradição da geografia regional francesa com a perspectiva dos estudos da percepção.

Dois autores, no entanto, ganham destaque por trazerem em suas reflexões abordagens que evidenciam e valorizam aspectos comportamentais e subjetivos nos estudos sobre a espacialidade humana e por terem, ao mesmo tempo, estimulado abordagens específicas sobre a influência da escalaridade nessas pesquisas. Um deles é o geógrafo sueco Torsten Hägerstrand, cujas investigações a partir dos anos 1950 se preocuparam em articular elementos subjetivos do comportamento humano a processos vinculados a espaços mais distantes do cotidiano. Suas pesquisas sobre a geografia do espaço-tempo estimularam reflexões sobre o que o autor chama de "espaços comportamentais" (HÄGERSTRAND, 1975), importantes de serem enfatizados porque, segundo ele, a "[...] escala da sobrevivência, escala prática ou, se você preferir, escala de engenharia, em outras palavras a arena da atividade social cotidiana, dos empreendimentos econômicos e arranjos físicos não é muito tratada como um problema teórico fundamental." (HÄGERSTRAND, 1975, p. 5, tradução livre). Apesar de não compartilhar as mesmas referências epistemológicas, outro autor interessado no espaço vivido e influente no debate escalar foi John Hart, famoso por seus estudos regionais. Em seu escrito mais lembrado na literatura anglófona da década de 1990 ("The highest form of the geographer's art", 1982), o autor sustenta a importância de se atentar para a relação entre o tamanho da região (chamado por ele de "escala") e a quantidade de detalhes do estudo apropriados a essa dimensão - uma vez que, segundo ele, "[a] escala de um estudo regional irá determinar quando uma parte particular da superfície da Terra é tratada como um ponto ou como uma área" (HART, 1982, p. 23, tradução livre). Sua peculiaridade em relação à Nova Geografia fica nítida quando coloca que "[r]egiões são dispositivos artísticos subjetivos e devem ser formadas para se ajustar às mãos de um usuário individual. Não pode haver definição padrão para uma região e não há regras universais para reconhecer, delimitar e descrever regiões" (HART, 1982, p. 21-2, tradução livre).

Em comparação com as preocupações neopositivistas, hegemônicas até então na Geografia, essas novas perspectivas abordavam o problema das escalas de forma a recolocar os aspectos qualitativos em debate. As diferentes percepções de mundo, consideradas especialmente na perspectiva da experiência, questionaram novamente os limites das divisões espaciais feitas até então, sublinhando a importância de não desprezar os elementos subjetivos na busca pela compreensão da espacialidade de processos sociais que influenciavam o cotidiano dos agentes.

Outra fonte importante para os debates ocorridos a partir do final da década de 1980 sobre as escalas geográficas foram as influências do pensamento marxista na Geografia. Os trabalhos elaborados sob essas bases ressaltavam o papel dos agentes sociais e de sua espacialidade no processo de produção do espaço das relações sociais. Assim, a partir daquela década "[...] geógrafos político-econômicos começaram a ir além disso para argumentar que o espaço e, por implicação, a escala, é produzido através de processos político-econômicos característicos de um certo sistema social" (McMASTER e SHEPPARD, 2004, p. 15, tradução livre).

No que envolve a influência que essas abordagens exerceram sobre o debate a respeito do problema das escalas geográficas, as obras mais lembradas pela literatura são as de Peter Taylor 
$(1981,1987)$ e Neil Smith $(1988) .{ }^{2}$ No caso do primeiro, foi ao incorporar e espacializar as reflexões de Immanuel Wallerstein, a partir da década de 1980, que sua influência no debate sobre as escalas geográficas cresceu. Taylor (1982) passou a tomar a escala geográfica como princípio básico para organizar o espaço a partir de uma perspectiva materialista, sugerindo que três diferentes escalas geográficas deveriam ser levadas em conta: a global, a nacional e a urbana (TAYLOR, 1981). Sua proposta de uma geografia política materialista "[...] posiciona a escala da realidade onde o capital finalmente se realiza no mercado mundial, a escala da ideologia onde o estado distorce o mercado e a escala da experiência onde os resultados do mercado são sentidos nas localidades" (TAYLOR, 2004, p. 217, tradução livre). Sua interpretação do sistema-mundo em um arranjo de três escalas concêntricas determinadas pela global (a mais externa e abrangente) é sua sugestão para a base de uma economia política de escala. ${ }^{3}$

Já as ideias de Smith sobre as escalas geográficas foram as que exerceram a maior influência no debate anglófono a respeito da escalaridade a partir da década de 1990, pois cumprem papel central em sua teoria do desenvolvimento desigual (SMITH, 1988). Criticando Taylor, Smith advoga em favor de uma abordagem das escalas geográficas centrada na esfera da produção. Suas elaborações se baseiam na explicitação do papel das escalas geográficas na dialética entre a diferenciação e a igualização do espaço geográfico no processo de desenvolvimento do capitalismo. Ele argumenta que a expansão da sociedade capitalista é conduzida pelo capital produtivo, exigindo investimentos em infraestruturas diversas (ferrovias, estradas, fábricas, campos etc.). Tais elementos do ambiente construído seriam as formas concretas e imobilizadas por meio das quais o capital se fixa no espaço. Acontece que a materialização do capital no ambiente construído gera com frequência crises de super acumulação que desvalorizam o capital em um formato imóvel e dificultam sua transferência para outros circuitos ou setores. A sobrevivência do capital dependeria, portanto, da mobilidade do capital circulante em períodos de desvalorização rápida. Por isso, ele aponta que uma questão central nessa sociedade é a possibilidade ou não de a produção capitalista resolver tais contradições por meio da produção de "fixos espaciais". A compreensão da escala geográfica, segundo ele, ajudaria no entendimento desse desenvolvimento desigual do capital, já que a tendência ao equilíbrio espacial implicaria a produção e diferenciação de espaços absolutos em

\footnotetext{
2. É crucial lembrar, porém, a relevância das reflexões de Yves Lacoste sobre as escalas geográficas e da incidência das ideias de David Harvey nos debates sobre o conceito. Ver DAVIDOVICH (1978), GONZÁLEZ (2003) e MOORE (2008). No que envolve Lacoste, suas reflexões são geralmente desconsideradas pelos escritos anglosaxões, conforme destacou SOUZA (2013). Na geografia brasileira, porém, sua importância é enfatizada desde o final da década de 1980 (BAHIANA, 1986), tendo sido relembrada mais tarde em outras ocasiões (CASTRO, 1995; SOUZA, 2002, 2006, 2013; GRANDI, 2015). Sobre as principais críticas que Lacoste recebeu nesse contexto, ver CASTRO (1995) e a introdução à versão brasileira do livro "A geografia - isso serve, em primeiro lugar, para fazer a guerra" escrita por José William Vesentini. As contribuições de Lacoste ao tema das escalas geográficas ainda merecem ser estudadas com maior afinco uma vez que compõem partes importantes de diferentes obras do autor. Atenção redobrada deve ser dada sobretudo às ideias de uma espacialidade diferencial - na qual os níveis de realidade (expressos em termos de conjuntos espaciais) se superpõem e se articulam tendo como referência as práticas espaciais cotidianas dos sujeitos (LACOSTE, 1988) - e de um espaço folheado, resultante de um processo de construção forjado no âmbito das práticas sociais (BAHIANA, 1986). David Harvey, por sua vez, em "Os limites do capital" (HARVEY, 1982) aborda as escalas geográficas partindo das limitações impostas à capacidade organizacional capitalista pelas tensões observadas entre fixidez e movimento, concentração e dispersão, compromissos locais e preocupações globais. Tais limitações levariam o capitalismo a ter que explorar e modificar continuamente seus arranjos organizacionais, criando estruturas de organização hierárquicas encaixadas ("nested hierarchical structures of organization") que ligam os aspectos particulares e locais aos seus objetivos em nível global e que definiriam uma variedade de escalas. Essas estruturas, em sua opinião, operam como "dispositivos de transmissão que relacionam ações particulares concretas aos efeitos globais do trabalho abstrato e, assim, confirma a economia política que integra o indivíduo na totalidade complexa da sociedade civil." (HARVEY, 1982, p. 424) [tradução livre]

3. Muitos trabalhos da década de 1990 sobre o tema das escalas geográficas seguiram o enquadramento proposto por Taylor. Sobre isso, ver MARSTON (2000) e HEROD (2011). Seu trabalho, porém, não foi imune a críticas, como as de MARSTON (2000), SMITH (1988) e HEROD (2011).
} 
escalas particulares da atividade social agrupadas em "[...] uma hierarquia cada vez mais sistemática de escalas espaciais" (SMITH, 1988, p. 196). Nesse "movimento de vaivém" que o capital faz entre áreas "desenvolvidas" e "subdesenvolvidas" na busca por explorar oportunidades econômicas de uma e evitar custos e riscos de outra é onde estaria a base do desenvolvimento desigual. É, portanto, a questão da utilidade da produção de fixos espaciais para o equilíbrio do processo de acumulação de capital que leva Smith a preocupar-se com a maneira como as várias escalas nas quais o capitalismo se organiza vêm à existência (HEROD, 2011).

\begin{abstract}
Em resumo, o impulso em direção à universalidade, sob o capitalismo, traz somente uma limitada igualização dos níveis e das condições de desenvolvimento. O capital produz escalas espaciais distintas (espaços absolutos) dentro dos quais o impulso para igualização está concentrado. Mas só pode ser realizado por aguda diferenciação e por contínua rediferenciação do espaço relativo, tanto entre as escalas quanto dentro delas. As escalas por si mesmas não são fixas, mas se desenvolvem (aumentando suas angústias e problemas correlatos) dentro do desenvolvimento do próprio capital. E não são impermeáveis; as escalas urbanas e nacionais são produtos do capital internacional e continuam a ser moldadas por ele. Mas a necessidade de escalas separadas e de sua diferenciação interna é fixa. Isto oferece o último elemento básico para a teoria do desenvolvimento desigual. (SMITH, 1988, p. 211)
\end{abstract}

As reflexões de Lacoste, Harvey, Taylor e Smith são partes das contribuições iniciais da geografia crítica marxista ao tema das escalas geográficas. Sua inovação ao incorporarem em suas reflexões o conteúdo político que permeia os processos de divisão e organização das unidades espaciais evidenciou o fato de que tais processos sempre foram permeados pelos interesses de exercer poder sobre o comportamento de populações e sujeitos (GRANDI, 2016). A partir da década de 1970 e, em especial, durante a década de 1980, portanto, são construídas as bases para que os desdobramentos práticos da escalaridade no sentido da produção de relações de poder específicas sejam tematizados. Tais referências deixaram como legado a politização da escala geográfica que, no decorrer das décadas seguintes, foi explorada com ânimo pela literatura anglófona.

\title{
A "abertura" do conceito de escala geográfica
}

A partir da década de 1990, o debate sobre o conceito de escala geográfica cresceu em meio à literatura anglo-saxã, embebida de fatores que contribuíram para o que ficou conhecido como a "abertura" do conceito de escala geográfica. Dentre tais aspectos figuram, especialmente, o destaque da narrativa da "crescente globalização" e a explicitação da relevância política dos processos de escalarização (MARSTON, 2000; MOORE, 2008; HEROD, 2011). ${ }^{4}$

As contribuições de alguns trabalhos influentes nas discussões anglófonas sobre a "abertura" desse conceito permitem organizar o debate anglófono sobre as escalas geográficas do período posterior à década de 1990 inicialmente ao redor de três diferentes eixos de questionamentos, intimamente articulados e muito raramente abordados de forma específica ou individualizada (Figura 1). ${ }^{5}$ Por um lado, a natureza das escalas geográficas é abordada, questionando-se sobre o caráter material ou discursivo e, ao mesmo tempo, se elas seriam categorias analíticas ou categorias da prática social. Ligadas a esse eixo estão também diferentes opiniões sobre as escalas serem vistas enquanto categorias ontológicas ou epistemológicas. Outro eixo de reflexões diz respeito à forma das escalas geográficas, no qual figuram dúvidas sobre as escalas serem melhor compreendidas

4. Para um exemplo de trabalhos diretamente baseados em Lefebvre, ver BRENNER (2000).

5. Trato aqui basicamente dos trabalhos de MARSTON (2000), GONZÁLEZ (2003), McMASTER e SHEPPARD (2004), MOORE (2008), MacKINNON (2010) e HEROD (2011). Outro trabalho importante sobre o tema é a coletânea organizada por HEROD e WRIGHT (2002) 
enquanto áreas contínuas com limites definidos ou como nós ligados entre si através de redes sócioespaciais. Por fim, há também debates quanto à organização das escalas geográficas, onde são encontradas perspectivas que consideram as configurações escalares de maneira verticalizada ou horizontalizada, além de questionarem-se quanto a existência ou não de hierarquias entre elas. Esses dois principais assuntos relativos à organização das escalas podem ser explicitados por meio das diferentes metáforas escalares que animam as reflexões que se dedicam ao tema. Ainda quanto à organização das escalas, ganha destaque o tema da política de escalas e da política escalar.

Figura 1 - Eixos do debate recente sobre o conceito de escala geográfica nos trabalhos em língua inglesa pós-1990

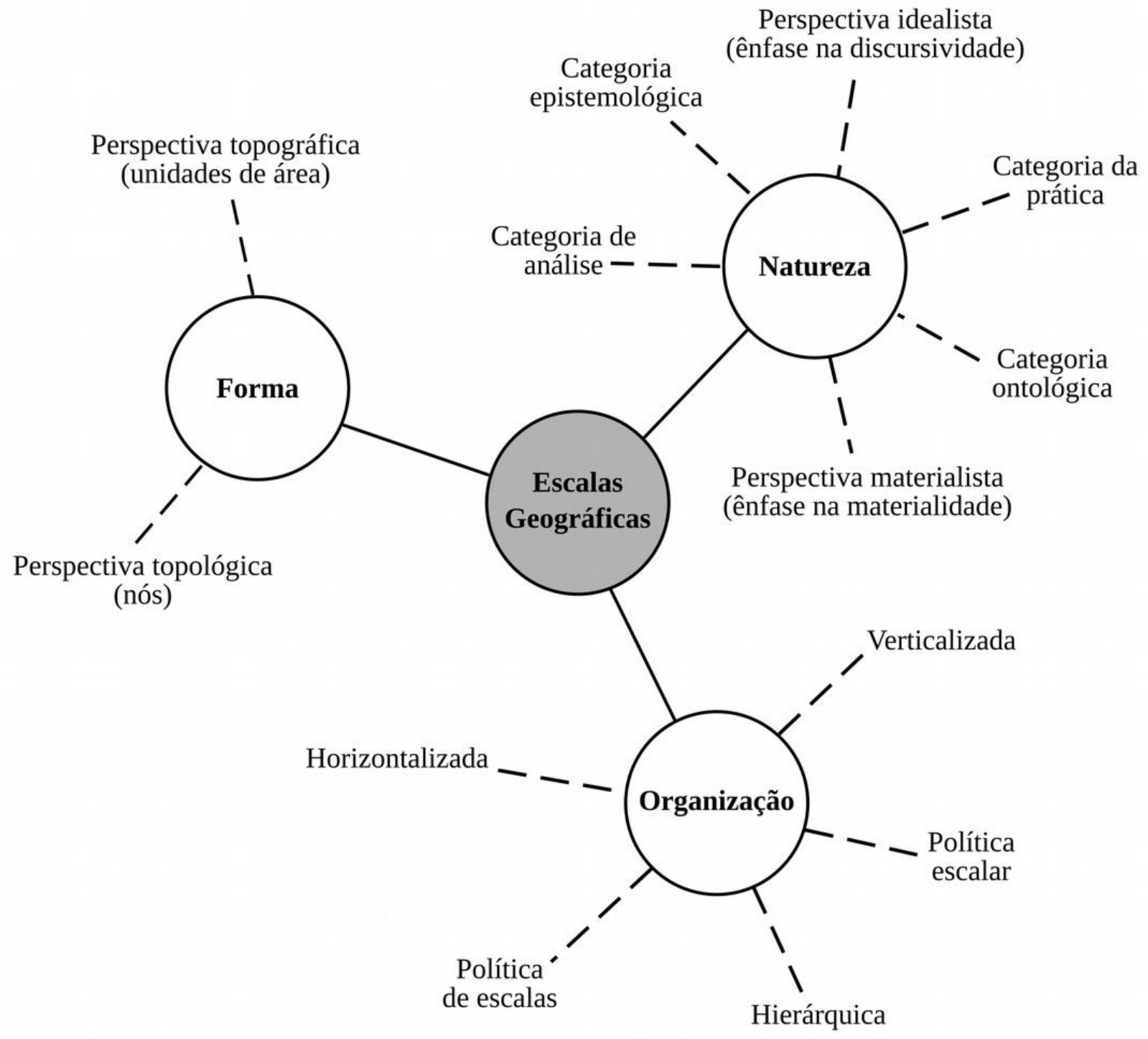

Fonte: elaboração própria

Antes de apresentar rapidamente cada um desses eixos, porém, é relevante expor brevemente os poucos consensos desse debate. O principal ponto de convergência é também o mais geral: o acordo sobre a importância de se assumir uma abordagem construcionista a respeito das escalas 
geográficas (MARSTON, 2000; GONZÁLEZ, 2003; SHEPPARD e McMASTER, 2004; MOORE, 2008). Isso implica concebê-las não mais como categorias fixas e com características definidas previamente, mas sim considerá-las como sendo construídas a partir de processos sociais dinâmicos. Suas especificidades, antes vistas como dadas a priori ou definidas ontologicamente, viraram objetos de reflexões sistemáticas. As unidades, seus limites, sua coerência como unidades espaciais, a importância relativa de cada unidade - comparada tanto com outras unidades "na mesma escala" quanto em relação às demais escalas - tornam-se aspectos vistos como mutáveis, destacando as análises multiescalares como outra das características fundamentais das perspectivas construcionistas que "[...] busca[m] perguntar como escalas particulares vem à existência através de fenômenos particulares e como sua importância relativa muda com o tempo" (SHEPPARD e McMASTER, 2004, p. 261, tradução livre). Além disso, tais investigações geraram um novo olhar sobre os aspectos inerentemente espaciais da política (MOORE, 2008; MacKINNON, 2010). Isso ocorreu em parte porque tal conceito passou a ser considerado como permeado e constituído por relações de poder (GONZÁLEZ, 2003) e, por outro lado, porque a importância da escalaridade na construção de diferentes relações de poder também ganhou destaque. Assim, as escalas geográficas foram identificadas como um dos âmbitos de mobilização e engajamento social vinculado à mudança ou à conservação das relações sociais existentes.

Para além dessas considerações gerais, no entanto, os debates tenderam a seguir caminhos diversos e algumas vezes dificilmente convergentes, oportunizando a emergência de diferentes trajetórias em termos teóricos, filosóficos, epistemológicos e metodológicos (SHEPPARD e MCMASTER, 2004), sendo que certas abordagens dessa discussão ficaram mais nítidas somente a partir do final da primeira década dos anos 2000 (MOORE, 2008; MacKINNON, 2010; HEROD, 2011).

\subsection{Natureza}

Duas diferenciações merecem destaque em meio ao consenso ao redor da importância de um olhar construtivista sobre as escalas geográficas. Primeiramente, as escalas vêm sendo pensadas enquanto entidades que existem material e concretamente no mundo ou, por outro lado, como uma construção epistemológica presente, em última análise, na mente de quem pensa sobre a organização espacial. Em segundo lugar, as escalas vêm sendo tratadas ou como categorias analíticas ou enquanto categorias da prática social.

\subsubsection{Categoria ontológica ou epistemológica? Analítica ou da prática? Com ênfase na discursividade ou materialidade?}

Alguns autores recentemente apontaram as diferentes perspectivas filosóficas dos trabalhos sobre o tema (MOORE, 2008; MacKINNON, 2010; HEROD, 2011). Na opinião deles, as reflexões têm sido realizadas ao redor de um continuum difuso entre dois polos: um materialista e outro idealista. A principal diferença entre essas perspectivas estaria no questionamento sobre se as escalas geográficas seriam objetos com existência real prévia às reflexões da razão humana ou não (HEROD, 2011), referindo-se diretamente tanto à natureza ontológica ou epistemológica dessas categorias quanto à ênfase de seus estudos dever estar em sua materialidade ou em sua dimensão discursiva. ${ }^{6}$ Mas há, obviamente, trabalhos que tensionam as fronteiras entre essas abordagens. ${ }^{7}$

6. Ver JONES (1998) para uma abordagem que entende as escalas como mecanismos epistemológicos.

7. Ver, por exemplo, COX (1998), HOWITT (1998, 2003), MARSTON (2000) e MacKINNON (2010). Os trabalhos inspirados no pós-estruturalismo, a rigor, tampouco se encaixariam nesse continuum. 
As pesquisas mais próximas ao primeiro polo têm inspiração predominantemente marxista. Parte importante de suas reflexões tem sido direcionada para a chamada economia política de escalas geográficas (TAYLOR, 1982), enfatizando perspectivas político-econômicas e sua produção social. Nelas é destacada a dimensão material das escalas, entendidas como elementos da realidade que exercem influência e têm desdobramentos concretos sobre o mundo. Ocorreriam disputas político-econômicas por tais referenciais materiais concretos existentes na natureza e construídos pelas sociedades. Os escritos inspirados nessa perspectiva são bastante variados, com novas abordagens sobre temas usuais nos estudos sobre o espaço social, elaborações conceituais próprias e referenciais analíticos inovadores. Exemplos disso podem ser vistos nas ideias de fixos escalares, reescalamento, política de escalas, salto de escalas, dobramentos escalares e estruturação escalar, dentre outras, cada vez mais difundidas nas produções estrangeiras - o que não significa que esses termos sejam exclusivos das reflexões baseadas nessa concepção ontológica das escalas. ${ }^{8}$

Já em relação ao polo mais próximo de uma perspectiva idealista, por outro lado, sobressai-se a inspiração identificada por alguns autores como neo-kantiana (MOORE, 2008; HEROD, 2011) e, por outros, como pós-estruturalistas -ainda que estas difiram profundamente das abordagens neokantianas, inclusive em termos político-filosóficos. Diferente das abordagens anteriores, estas produções destacam aspectos e dinâmicas ligadas à dimensão discursiva das escalas geográficas, entendendo-as enquanto metáforas espaciais da realidade elaboradas socialmente. As disputas se dariam no âmbito da nomeação e da organização das diferenças espaciais do mundo. Assim, a escala não seria "[...] simplesmente um fato externo esperando ser descoberto, mas uma forma de enquadramento de concepções sobre a realidade." (DELANEY e LEITNER, 1997, p. 94-95, tradução livre). Por sua vez, noções próprias também têm sido elaboradas nesse rol de trabalhos, como as de imagens escalares, narrativas escalares, metáforas escalares, práticas escalares, configurações ou arranjos escalares, performatividade da escala, efeitos escalares, genealogia política das ontologias escalares, dentre outras. Mas vale ressaltar que tampouco tais termos são encontrados exclusivamente em trabalhos que se aproximam dessas concepções filosóficas. ${ }^{9}$

As controvérsias e discussões originadas nos diferentes posicionamentos frente a essas questões conviveram nos últimos vinte anos. Enquanto durante os anos 1990 predominou a aproximação com o primeiro polo, na década seguinte tais concepções foram alvo de críticas mais frequentes por parte de abordagens que adotavam um ponto de vista relacional, aberto e múltiplo em relação às escalas geográficas (MacKINNON, 2010), sugerindo debates sobre "[...] como as escalas são pensadas e como isso forma consciência ao invés de como as escalas como entidades materiais estruturam e são estruturadas por processos econômicos, políticos e ambientais" (HEROD, 2011, p. 56, tradução livre). Ainda assim, é crucial destacar que as diferentes abordagens mais se complementam do que se excluem ao ressaltarem aspectos igualmente fundamentais às reflexões sobre as escalas geográficas e sobre o papel da escalaridade como dimensão constituinte da espacialidade humana (MacKINNON, 2010; HEROD, 2011; GRANDI, 2015).

\subsubsection{Categorias analíticas ou categorias da prática?}

Outra discussão que emerge diz respeito à questão sobre se as escalas deveriam ser consideradas categorias de análise ou categorias da prática (KAISER e NIKIFOROVA, 2008; MOORE,

8. Alguns trabalhos que poderiam se encaixar nessa abordagem em diferentes níveis seriam os de TAYLOR (1981, 1982, 1987), SMITH (1993), SWYNGEDOUW (1997a, 1997b, 2000, 2003, 2004) e BRENNER (2000), dentre outros.

9. Produções que em alguma medida poderiam ser aproximadas dessa perspectiva: HART (1982), FERGUSON e GUPTA (2002), COLLINGE (2005, 2006), MOORE (2008) e KAISER e NIKIFOROVA (2008), dentre outros. 
2008) ${ }^{10}$. O melhor exemplo vem das elaborações de Adam Moore, que argumenta que boa parte da literatura nessa discussão - em especial aquela ancorada na economia política - aproxima de maneira pouco criteriosa compreensões das escalas como categorias da prática social e enquanto categorias analíticas. Trazendo exemplos dessas aproximações em trabalhos de Peter Taylor, Neil Smith e Erik Swyngedow, Moore afirma que da mesma forma que certos cientistas sociais tomam as nações como realidades ontológicas ao invés de vê-las como realidades epistemológicas (reificando nacionalidades), as escalas geográficas também acabam sendo reificadas. Acontece que, pelo contrário, as escalas seriam também ficções "[...] que informam nossas compreensões populares da organização espacial do mundo" (MOORE, 2008, p. 208, tradução livre), devendo ser estudadas como tais.

\subsection{Forma}

Além dos debates sobre sua natureza, dois tipos de concepções sobre a forma das escalas geográficas surgem na literatura trabalhada: uma perspectiva topográfica e outra perspectiva topológica ${ }^{11}$. Os trabalhos que enfocam as escalas de maneira topográfica são mais comuns na literatura e veem as escalas como unidades de área, contêineres geográficos mais ou menos rígidos onde cada escala definiria um espaço absoluto mais ou menos específico delimitado por fronteiras mutuamente excludentes, não raro como "[...] entidades separadas e distinguíveis no interior de uma hierarquia de divisões espaciais [...]" (HEROD, 2011, p. 14, tradução livre).

Por outro lado, as perspectivas que entendem as escalas de forma topológica voltam sua atenção para as escalas não como entidades espaciais fechadas, mas sim enquanto partes de redes sócio-espaciais. Tal acepção permite refletir sobre espaços particulares como estando simultaneamente conectados a outros sem uma relação necessariamente hierárquica. Uma abordagem topológica teria ao menos quatro vantagens: as redes se expandem pelo espaço, mas não o cobrem, evitando serem limitadas por fronteiras; as redes também são de mais difícil regulação a partir dos espaços geográficos existentes por transcenderem os limites de governo hierarquizado; os espaços que fazem parte de uma rede são flexíveis e modificam-se frequentemente; os espaços que compõem a rede podem se sobrepor e penetrar uns aos outros (LEITNER, PAVLIK e SHEPPARD, 2002) ${ }^{12}$. Tais trabalhos enriqueceram e polemizaram os debates com sua diversidade, indo de propostas como expurgar o conceito de escala da geografia (MARSTON, JONES e WOODWARD, 2005) a ideias como considerarmos as escalas enquanto "receptáculos de devir" que proveem o ordenamento social e espacial prévio à própria significação (COLLINGE, 2005).

\subsection{Organização}

O terceiro eixo dos debates anglófonos sobre o tema envolve a organização e o funcionamento das escalas geográficas, debatendo as maneiras como elas são postas em relação umas com as

\footnotetext{
10. Tal problema decorre da influência do trabalho de BRUBAKER e COOPER (2000) no debate sobre a escala geográfica. Essa distinção entre tais tipos de categorias também é vista, ainda que em relação a outro objeto (o conceito de cultura), em análises como a de SEWELL (1999).

11. O uso desses termos é controverso, pois suas origens etimológicas não indicam uma distinção entre unidades de área e pontos articulados em rede: grapho faz referência ao desenho, enquanto logos remete à ideia de razão). Sigo aqui a terminologia utilizada por HEROD (2011).

12. Para outras considerações sobre as escalas geográficas desde uma perspectiva topológica, ver COX (1998), JONES (1998), JUDD (1998), LATHAM (2002), BRENNER (2001), MARSTON e SMITH (2001), SHEPPARD (2002), LEITNER (2004), COLLINGE (2005), MARSTON, JONES e WOODWARD (2005), KAISER e NIKIFOROVA (2008) e MOORE (2008), dentre outros.
} 
outras, formam diferentes configurações ou arranjos escalares ${ }^{13}$ e influenciam diretamente a chamada gestalt das escalas ${ }^{14}$. As distintas abordagens a respeito dos arranjos escalares também influem nas maneiras como são pensadas suas articulações, resultando em metáforas escalares diferentes e em maneiras específicas de se conceber as relações entre as escalas geográficas e a eficácia política das práticas sócio-espaciais.

\subsubsection{Arranjos e metáforas escalares}

São ao menos dois os assuntos ao redor dos quais os debates sobre as configurações e arranjos escalares giram. Por um lado, levantam discussões sobre a verticalidade ou a horizontalidade dessa organização. Por outro, questionam a existência de hierarquias entre as escalas. Conforme diferentes autores destacam (SMITH, 1993; SWYNGEDOUW, 1997b; HOWITT, 1998; HEROD, 2011), refletir sobre tais aspectos por meio da análise de diferentes metáforas escalares é uma abordagem que ajuda a vislumbrar as diferentes maneiras como as escalas geográficas podem ser organizadas e como, por consequência, podem ser pensadas as interações entre elas e os processos sócioespaciais. Elas moldam as concepções sobre a articulação das partes do espaço em diferentes totalidades e permitem a politização dessas compreensões (SMITH, 1993), conformando as maneiras como pensamos, interagimos e ensinamos (HOWITT, 1998; HEROD, 2011) e constituindo diferentes narrativas escalares que constroem discursos explicativos sobre 0 mundo (SWYNGEDOUW, 1997b; GONZÁLEZ, 2003). Uma compilação inicial e ilustrativa de metáforas escalares é feita por Andrew Herod (2011): a escada, os círculos concêntricos, a matrioska, as raízes de árvores, os buracos de minhoca e a teia.

As três primeiras metáforas (Figura 2) veem as escalas em termos contínuos, ou seja: como unidades de área. A escada e os círculos concêntricos (ou suas variações) são as metáforas mais comuns, tanto na literatura que trata especificamente dos debates teórico-conceituais sobre as escalas geográficas, quanto nas pesquisas sócio-espaciais de forma geral. Na metáfora da escada, cada degrau seria uma diferente escala, ainda que não precisem ser do mesmo tamanho (similar à ideia de uma pirâmide) (GONZÁLEZ, 2003). Essa metáfora descreve hierarquias escalares essencialmente verticalizadas e assume que as fronteiras entre as escalas seriam nitidamente identificáveis. Seria possível, então, "subir" ou "descer" as escalas, pois elas estariam acima ou abaixo umas das outras como patamares espaciais verticalmente dispostos e que não raro estariam relacionados a diferentes posições nas relações de poder. Apesar de compartilhar muitas características com a metáfora da escada, na metáfora dos círculos concêntricos o aspecto dimensional das escalas é visto em termos horizontais, de forma que se pode transitar entre as escalas movendo-se entre elas. A relação horizontal também estabelece que o "global", por exemplo, não estaria "acima" das outras escalas, mas sim seria "maior" que elas. Nessa metáfora, portanto, as escalas "maiores" abrangem as escalas "menores", diferentemente da metáfora anterior. Tal relação de abrangência é similar àquela vista na metáfora da matrioska. Ambas nos dão os exemplos mais explícitos daquilo que se chama de escalas agrupadas, encaixadas ou aninhadas ("nested scales"). No entanto, além de também partir do pressuposto de que as escalas têm limites nítidos, a metáfora

13. Esse termo é utilizado sobretudo por MOORE (2008). COLLINGE (2006) utiliza a expressão "esquema (ou sistema) de escalas" e Dominique MASSON (2006) se refere a esses arranjos, no caso dos movimentos sociais, como "quadros referenciais da ação coletiva". Todas as expressões, no entanto, podem ser entendidas em sentido similar.

14. "(...) a forma pela qual diferentes escalas são postas em conjunto para formar um padrão geral e como olhar para elas de diferentes perspectivas pode resultar em compreensões muito diferentes da realidade material." (HEROD, 2011, p. 56, tradução livre) Ver também SMITH (1987). 
das bonecas russas mostra-se mais rígida do que as ideias anteriores por dois motivos: por um lado, cada boneca é apresentada como encaixando-se exclusivamente naquelas imediatamente maiores, de forma que a possibilidade de acontecerem "saltos de escalas" se apresenta mais distante; por outro, independentemente do "nível", as bonecas são sempre réplicas das demais, guardando como única variação o seu tamanho relativo. É o que pode ser chamado de determinismo escalar (GRANDI, 2015), quando se assume que aspectos encontrados em certas escalas determinam características das relações que ocorrem em outras.

Figura 2 - Metáforas da escada (esquerda), dos círculos concêntricos (centro) e da matrioska (direita)
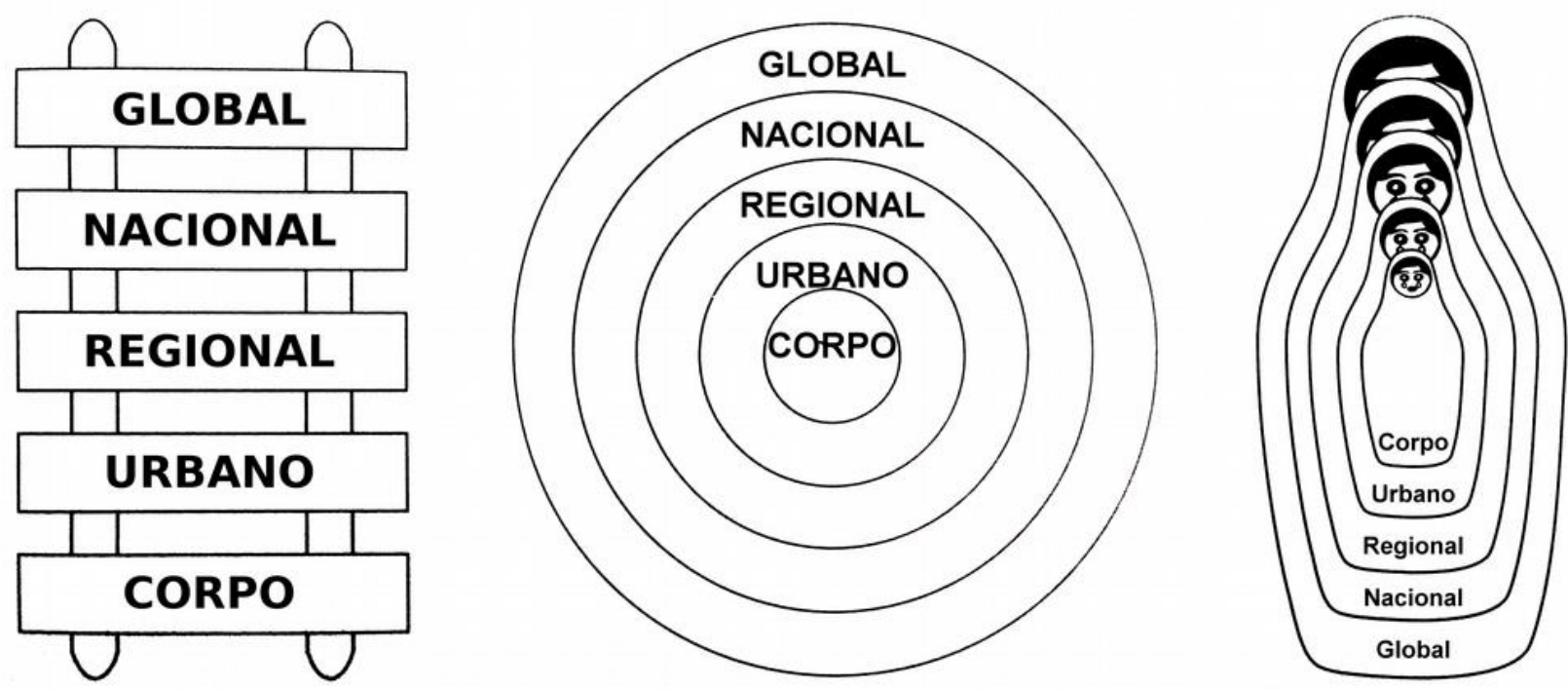

Fonte: HEROD (2011). Adaptado pelo autor

Considerando as três últimas metáforas resgatadas por Herod - as raízes de árvores, os buracos de minhoca e a teia de aranha - é nítido que elas partem da concepção das escalas enquanto nós organizados em diferentes tipos de redes, permitindo vislumbrar diferentes interconexões dos processos sócio-espaciais (Figura 3). Com essa perspectiva topológica, a metáfora das escalas organizadas como raízes de árvores traz uma ideia de oposição entre escalas frequentemente vistas como polos de um continuum. O que a difere das metáforas anteriores é que os limites entre as escalas não são definidos nitidamente. Além disso, o ponto no qual todas as raízes se encontram o tronco da árvore - faz referência à convergência ou divergência dos processos. Esse ponto pode ser tanto o "corpo" ou o "local" (onde se concretizam processos mais dispersos) quanto o "global" (que abarcaria as outras escalas). Dessa forma, apesar de haver somente um ponto de "entrada/saída", a flexibilidade quanto a ele permite que as conexões possam ser concebidas em ambas as direções - "global" $\leftrightarrow$ "corpo", por exemplo. Isso é diferente no caso de se ver as escalas geográficas organizadas conforme buracos de minhoca, pois nessa metáfora não há somente uma "entrada/saída" para os processos, permitindo que as conexões possam ocorrer em múltiplos sentidos. Assim, mesmo que a superfície de "entrada/saída" ainda sirva como uma referência, a metáfora dos buracos de minhoca se aproxima mais da lógica rizomática do que a anterior - além de compartilhar com ela as características da organização em rede e dos limites indefinidos entre as escalas. Estes dois últimos traços também são compartilhados pela metáfora da teia de aranha, que 
dialoga com a metáfora anterior por seu potencial descentralizador ${ }^{15}$ uma vez que também permite a circulação de um ponto a outro sem a necessidade de se passar por um centro - algo inviável na metáfora das raízes das árvores. Por fim, a metáfora da teia ainda é diferente das últimas duas por ser basicamente uma referência bidimensional, enquanto as anteriores permitem uma abordagem tridimensional das organizações escalares.

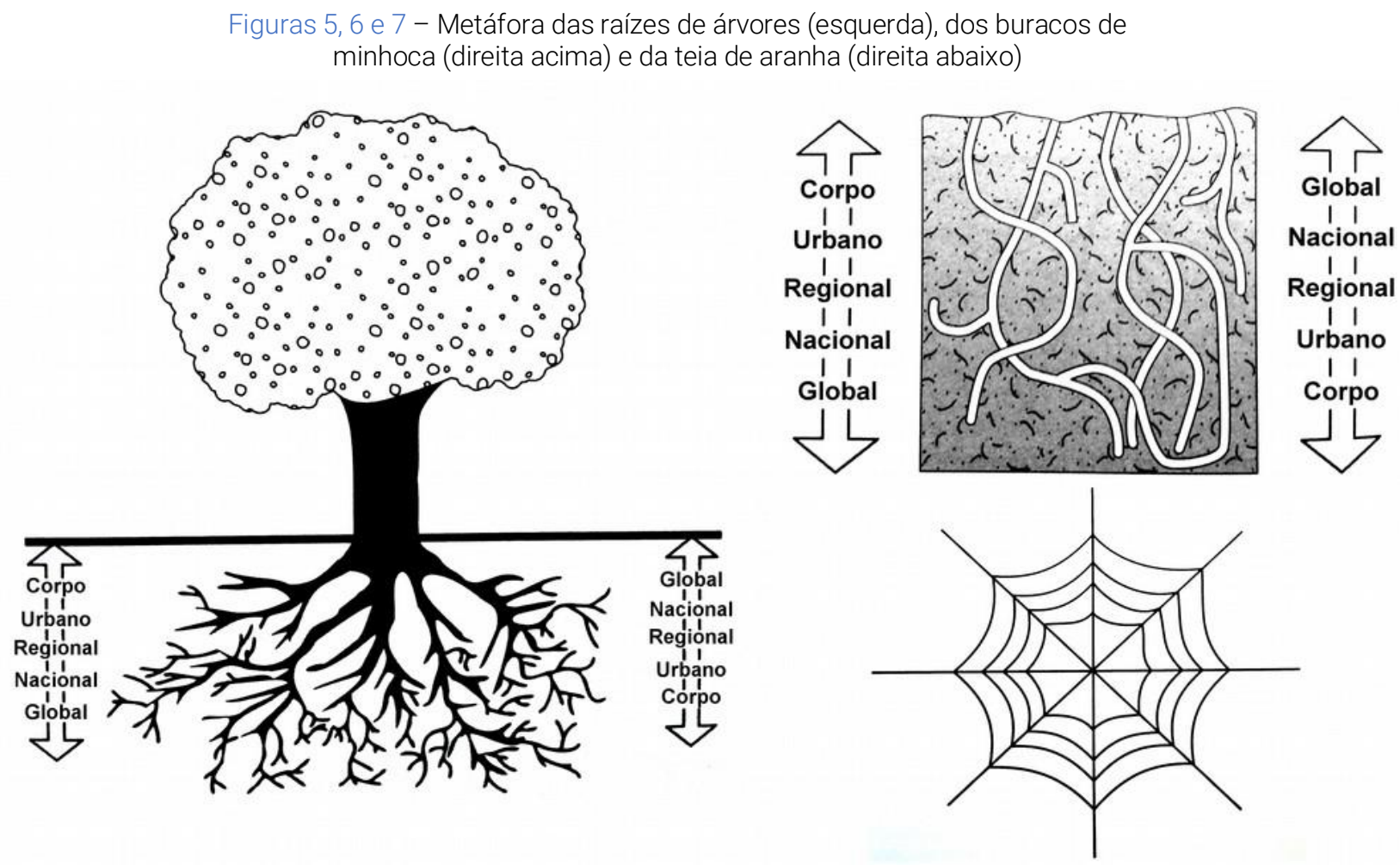

Fonte: HEROD (2011). Adaptado pelo autor

Diante dessas metáforas escalares, há quem diga que as diferentes perspectivas apresentadas compartilham a concepção de que as escalas geográficas conformariam sempre hierarquias específicas, fossem elas verticalizadas ou horizontalizadas (HEROD, 2011). Outras abordagens, porém, afirmam que um dos princípios desenvolvidos no interior do debate sobre as escalas geográficas seria exatamente a noção de que os arranjos escalares devem ser concebidos como indo além de sua concepção hierárquica (GONZÁLEZ, 2003). ${ }^{16}$

Essas considerações sobre as características de diferentes metáforas espaciais permitem elaborar uma tipificação introdutória dos arranjos ou configurações escalares:

(a) Arranjos ou configurações escalares hierárquicas verticalizadas: neles as escalas são vistas geralmente em termos topográficos e representadas por metáforas como a escada, a pirâmide, os patamares ou os fractais. Nos casos em que as escalas são vistas topologicamente, esses arranjos tendem a ser representados como as raízes de árvores, que apresentam uma centralidade nítida.

15. HEROD (2011) ressalta que a existência ou não de um centro na teia também é questionada por alguns autores visando enfatizar o potencial descentralizador dessa metáfora.

16. A autora se baseia em PECK (2002) e HOWITT (1998). Para reflexões sobre a importância de se observar as assimetrias de poder quando se adota uma inspiração topológica das escalas geográficas, ver SHEPPARD (2002) e LEITNER et al (2002). 
(b) Arranjos ou configurações escalares hierárquicas horizontalizadas: Quando vistas enquanto unidades de área, as escalas organizadas dessa forma são representadas por metáforas como os círculos concêntricos ou a matrioska. Já ao serem vistas em termos topológicos, tendem a ser representadas por metáforas como as teias de aranha que também possuem um centro nítido.

(c) Arranjos ou configurações escalares não-hierárquicas: ao serem vistas em termos topográficos, o arranjo escalar pode ser representado de forma similar a espacialidade diferencial apresentada por Lacoste (1988). Já se sua base é uma perspectiva topológica, ganham destaque as metáforas dos buracos de minhocas, rizomas e teias de aranha que não apresentem um centro definido.

\subsubsection{Arranjos escalares e poder: política de escala e política escalar}

A partir de meados da década de 1980, ganharam expressão os trabalhos que ressaltavam a organização das escalas geográficas e seu funcionamento como resultados e como influenciadores de processos sociais constituídos por meio de relações de poder. As relações entre escalas geográficas e a eficácia da prática política têm sido abordadas por pesquisas interessadas naquilo que vem sendo chamado de "política de escalas" (SOUZA, 2013). ${ }^{17}$

De maneira geral, o termo política de escalas tem sido empregado para destacar os processos políticos de contestação e lutas sociais por meio dos quais se dá a construção social das escalas geográficas (BRENNER, 2001), reconhecendo os diferentes recursos econômicos, políticos, informacionais e simbólicos à disposição dos distintos agentes sociais para que persigam seus objetivos. ${ }^{18}$ Mas as situações e práticas sócio-espaciais que têm sido abordadas sob esse rótulo são variadas. Algumas pesquisas consideram que a política de escalas diz respeito às formas como determinados atores movem-se entre diferentes escalas, contexto no qual ganham sentido as expressões "salto de escalas" ("scale jumping"), "reescalamento" ("rescaling") e "deslocamento escalar" ("scalar shift"), por exemplo (HEROD e WRIGHT, 2002). Outras investigações enfocam as formas como os agentes negociam suas práticas através de diferentes escalas geográficas e/ou atuam simultaneamente em múltiplas escalas, perspectiva que estaria na base das ideias de "negociação escalar" ("scalar negotiation"), por exemplo (HEROD e WRIGHT, 2002). Brenner (2001), por sua vez, sugere a existência de um sentido singular e um sentido plural para a expressão política de escalas, referentes respectivamente a uma "política de constituição de escalas" (gerando pesquisas sobre a política da casa, da região, do país, etc., por exemplo) e à "política da relação entre escalas" ${ }^{19}$

A ideia de "política de escalas" também foi alvo de críticas que chegaram a sugerir que sua imprecisão justificaria sua substituição por outras expressões. É difícil não observar, por exemplo, que ao se preocupar com a política de escalas muitas pesquisas têm se focado mais nas escalas geográficas do que nos processos sócio-espaciais que as constituem (HEROD e WRIGHT, 2002). As escalas continuariam sendo vistas, portanto, basicamente como um esqueleto, uma estrutura de resoluções espaciais previamente existentes através e por meio das quais a vida social se daria. Por isso as referências a saltos de escalas e negociações escalares arriscariam reificar as escalas

17. A expressão teria sido cunhada em 1990 por Neil Smith no posfácio da segunda edição de seu livro "Desenvolvimento desigual", lançado originalmente em 1984 (BRENNER, 2001).

18. Ver também HEROD e WRIGHT (2002). SOUZA (2010, p. 42), por sua vez, define a política de escalas como "(...) a articulação de ações e agentes operando em níveis escalares diferentes (isto é, que possuem magnitudes e alcances distintos) com a finalidade de potencializar efeitos, neutralizar ou diminuir o impacto de ações adversas ou tirar maiores vantagens de situações favoráveis".

19. Para comentário a esse respeito, ver GRANDI (2015). 
geográficas ao separá-las das práticas responsáveis por sua criação. Ao assumir isso se "[...] perde de vista que as escalas não existem exceto através das práticas sociais pelas quais elas são de fato constituídas" (HEROD e WRIGHT, 2002, p. 11, tradução livre). Segundo essa crítica, os atores sociais não "saltariam" escalas, mas sim constituiriam as escalas por meio de sua práxis social. A diferença estaria entre uma abordagem que vê as ações como acontecendo em e por meio do espaço e aquela que olha para as práticas sociais preocupadas com como elas de fato produzem o espaço (HEROD e WRIGHT, 2002).

Outra crítica contundente aos usos mais comuns da expressão política de escalas sugere sua substituição pela ideia de políticas escalares (MacKINNON, 2010), uma vez que não seriam as escalas geográficas em si os objetos de contestação por parte dos atores sociais, mas sim os processos e práticas sociais que seriam escalarmente diferenciados. A política escalar partiria de quatro elementos-chave: a crítica à ideia de política de escalas, pois as escalas não são o foco da atividade política, apesar de serem parte crucial dela; o uso estratégico das escalas pelos atores que visam alcançar os objetivos traçados por meio do manejo das dimensões materiais e discursivas das escalas; a atenção às influências que estruturas escalares preexistentes exercem sobre os processos, reconhecendo a importância dos atores, rotinas, práticas e redes para que essas interações aconteçam; e a possibilidade de criação de novos arranjos e configurações escalares que emerge a partir do contato das estruturas escalares herdadas e com os projetos sociais e políticos emergentes. Essas considerações demarcam diferenças de abordagem importantes: uma delas percebe as escalas geográficas como arenas fundamentais à eficácia da prática política (em geral identificada com o tema da política de escalas); outra entende essa relação sem considerar as escalas como o objetivo das práticas políticas em si, assumindo que são as ações que adquirem características escalares. Nesta perspectiva, portanto, é a ação que se adjetiva escalarmente, enfatizando a componente escalar da prática política.

\section{Considerações finais}

Apesar da necessidade de se aprofundar os estudos sobre a literatura nacional, um rápido resgate das produções brasileiras aponta contribuições pioneiras e originais sobre o tema das escalas geográficas já nas décadas de 1970 e 1980 (GRANDI, 2014). Isso, porém, não definiu as escalas como um debate conceitual central para nas pesquisas sócio-espaciais brasileiras, que já na década de 1990 tomaram outros rumos e distanciaram-se de vez da temática. Para ser justo, porém, não é possível dizer que o tema não foi trabalhado durante aquela década. Algumas produções trouxeram inclusive contribuições inovadoras ao debate e mantiveram o conceito ao menos no campo de visão das reflexões sobre a dimensão espacial da sociedade (HAESBAERT, 1993; CASTRO, 1995). Acontece que a tarefa de realizar reflexões teórico-conceituais mais sistemáticas sobre as escalas geográficas não foi levada adiante durante os anos 90 . Os motivos para isso, no entanto, não são nítidos até o momento, cabendo pensar sobre os motivos que levaram a literatura brasileira a não discutir o conceito de escala geográfica.

A "abertura" do conceito de escala geográfica no ambiente anglófono se deu especialmente a partir da influência de autores como Peter Taylor e Neil Smith (além de David Harvey). No contexto brasileiro, porém, as reflexões mais inovadoras foram elaboradas entre o final da década de 1970 e o início da década de 1990, dialogando especialmente com Lacoste, Harvey, Taylor ou outros autores. Curiosamente, no entanto, o diálogo com as ideias de Smith sobre as escalas geográficas foi incipiente. Além disso, seguindo a tradição da geografia brasileira, duas das principais contribuições ao debate desse conceito no país dialogavam mais com a literatura francesa do que com a inglesa 
(BAHIANA, 1986; CASTRO, 1995). Ainda assim, mesmo a referência francófona não inspirou um grande debate sobre o conceito no Brasil. Somente no início dos anos 2000 é que algumas menções a esse debate começaram a aparecer, especialmente motivadas pelo interesse no tema da política de escalas e parcialmente alimentadas pelas discussões fermentadas na literatura anglófona, mas importante destacar - também com contribuições inovadoras. Desde então a preocupação com as escalas geográficas retornou parcial e vagarosamente aos debates nacionais. Os investimentos teórico-conceituais sobre o assunto, no entanto, ainda são tímidos. Salvo as poucas exceções no país que identificaram parte do debate estrangeiro sobre as escalas geográficas, tal conceito segue sendo predominantemente tratado de maneira superficial em nossa literatura. Além disso, há poucos sinais de incorporação de uma perspectiva que se preocupe em observar e problematizar as dinâmicas sócio-espaciais responsáveis pela intrincada construção social das escalas e de seus arranjos nas pesquisas sócio-espaciais brasileiras. A complexidade, variedade e frequentes dicotomizações, não raro maniqueístas, encontradas nos debates sobre as escalas geográficas na literatura nacional e anglófona impactam, assim, o potencial que a compreensão da escalaridade como dimensão da espacialidade humana traz para a complexificação de nossa compreensão das relações entre a ação social e o espaço.

É no sentido de contribuir com reflexões sobre alternativas para superar ao menos essas barreiras iniciais que uma agenda de pesquisas comprometida com a dimensão escalar da produção do espaço ganha sentido. Compreender a trajetória desse debate na geografia brasileira, bem como investir em um diálogo intenso e necessariamente crítico com as produções estrangeiras sobre o tema e no engajamento empírico rigoroso embasado nas ideias que brotam desse debate, também são tarefas ainda a serem realizadas e que trazem consigo o potencial de arejar os olhares e suscitar novos caminhos e reflexões. 


\section{Referências}

BAHIANA, Luis Cavalcanti da Cunha. (1986) Contribuição ao estudo da questão da escala na geografia: Escalas em geografia urbana. Dissertação (Mestrado em Geografia), Programa de Pós-graduação em Geografia / UFRJ, Rio de Janeiro.

BAILLY, Antoine. GREER-WOOTEN, Bryn. (1983) Behavioural geography in Francophone countries. Progress in Human Geography, v. 7, n. 1, pp. 344-56.

BRENNER, Neil. (2000) The urban question as a scale question: reflections on Henri Lefebvre, urban theory and the politics od scale. Antipode, v. 24, n. 2, pp. 361-378.

BRENNER, Neil. (2001) The limits to scale? Methodological reflections on scalar structuration. Progress in human Geography, v. 25, n. 4, pp. 591-614.

CASTRO, Iná Elias de. (1995) O problema da escala. In: CASTRO, Iná Elias de. et al. (orgs.): Geografia: conceitos e temas. Rio de Janeiro: Bertrand Brasil.

COLLINGE, Chris. (2005) The différance between society and space: Nested scales and the returns of spatial fetishism. Env \& Plan D, v. 23, n. 2, pp. 189-206.

COLLINGE, Chris. (2006) Flat ontology and the deconstruction of scale: a response to Marston, Jones and Woodward. Transactions of the IBG, v. 31, pp. 244-251.

COX, Kevin. (1998) Spaces of dependence, spaces of engagement and the politics of scale, or: looking for local politics. Political Geography, v. 17, n. 1, pp. 1-23.

DAVIDOVICH, Fany. (1978) Escalas de urbanização: Uma perspectiva geográfica do sistema urbano brasileiro. Revista Brasileira de Geografia, v. 40, n. 1, pp. 51-82.

DELANEY, David. LEITNER, Helga. (1997) The political construction of scale. Political Geography, v. 16, n. 2, pp. 93-97.

FERGUSON, James. GUPTA, Akhil. (2002) Spatializing states: toward an ethnography of neoliberal governmentality. American Ethnologist, v. 29, pp. 981-1002.

GONZÁLEZ, Sara. (2003) La política de escalas en Bilbao: La construcción socio-política de un área metropolitana. Tese (doutorado em sociologia), Departamento de Sociologia, Universidade do País Vasco, Bilbao.

GRANDI, Matheus. (2014) As contribuições de Davidovich e Bahiana ao debate das escalas geográficas no Brasil. Geousp - Espaço e tempo, v. 18, n. 2, pp. 253-268.

GRANDI, Matheus. (2015) A construção escalar da ação no movimento dos sem-teto. Tese (Doutorado em Geografia), PPGG/UFRJ, Rio de Janeiro.

GRANDI, Matheus. (2016) Escalaridade: Notas sobre a divisão e a articulação do espaço. Anais do IV Encontro Nacional de História do Pensamento Geográfico \& II Encontro Nacional de Geografia Histórica. Belo Horizonte: COLTEC/UFMG; IGC/UFMG; UFU; PUCMINAS; AGB. pp. 232-249.

HAESBAERT, Rogério. (1993) Escalas Espaco-Temporais: Uma Introdução. Boletim Fluminense de Geografia, v. 1, n. 1, pp. 31-51.

HÄGERSTRAND, Torsten. (1975) Space, time and human conditions. In: KARLQVIST, A. LUNDQVIST, L. SNICKARS, F. (ed.): Dynamic Allocation of Urban Space. Estocolmo: Lexington Books.

HART, John. (1982) The highest form of the geographer's art. Annals of the Association of American Geographers, v. 72, n. 1, pp. 1-29.

HARVEY, David. (1982) The limits to capital. Oxford: Blackwell.

HEROD, Andrew. (2011) Scale. New York: Routledge.

HEROD, Andrew. WRIGHT, Melissa. (2002) Placing scale: an introduction. In: HEROD, Andrew. WRIGHT, Melissa (ed.): Geographies of power. Oxford: Blackwell, p. 1-14. 
HOWITT, Richard. (1998) Scale as relation: musical metaphors of geo graphical scale. Area, v. 30, n. 1, pp. 49-58.

HOWITT, Richard. (2003) Scale. In: AGNEW, John et al (ed.): A companion to political geography, Oxford: Blackwell, p. 138-57.

JONES, Katherine. (1998) Scale as epistemology. Political Geography, v. 17, n.1, p. 25-28.

JUDD, Dennis. (1998) The case of the missing scales: a commentary on Cox. Political Geography, v. 17, n. 1, pp. 29-34.

KAISER, Robert. NIKIFOROVA, Elena. (2008) The performativity of scale: The social construction of scale effects in Narva, Estonia. Env \& Plan D, n.26, p. 537-562.

LACOSTE, Yves. (1988[1976]) A geografia - isso serve, em primeiro lugar, para fazer a guerra. Campinas: Papirus.

LATHAM, Alan. (2002) Retheorising the scale of globalisation: Topologies, actor-networks and cosmopolitanism. In: HEROD, Andrew. WRIGHT, Melissa (2002) (ed.): Geographies of power. Oxford: Blackwell, p. 115-144.

LEITNER, Helga. (2004) The politics of scale and networks of spatial connectivity: transnational interurban networks and the rescaling of political governance in Europe. In: McMASTER, Robert; SHEPPARD, Eric. (orgs). Scale and Geographic Inquiry: Nature, Society, and Method. Oxford: Blackwell. p. 236-255.

LEITNER, Helga. PAVLIK, Claire. SHEPPARD, Eric. (2002) Networks, governance, and the politics of scale: inter-urban networks and the European Union. In: HEROD, Andrew. WRIGHT, Melissa (ed.): Geographies of power. Oxford: Blackwell, p. 274-303.

MacKINNON, Danny. (2010) Reconstructing scale: Towards a new scalar politics. Progress in Human Geography. v. 35, n. 1. pp. 21-36.

MARSTON, Sallie. (2000) The social construction of scale. Progress in Human Geography, v. 20, n. 2, pp. 219-242.

MARSTON, Sallie. JONES, Paul. WOODWARD, Keith. (2005) Human geography without scale. Transactions of the IBG, v. 30, pp. 416-432.

MARSTON, Sallie. SMITH, Neil. (2001) States, scales and households: limits to scale thinking? A response to Brenner. Progress in Human Geography, v. 25, pp. 615-19.

MASSON. Dominique. (2006) Escala geográfica e transnacionalização: análise sobre movimentos sociais e de mulheres. Caderno CRH, v. 19, n. 48, p. 445-459, Set./Dez.

MCMASTER, Robert. SHEPPARD, Eric. (2004) Introduction: Scale and Geographic Inquiry In: SHEPPARD, Eric; McMASTER, Robert (org.): Scale \& Geographic Inquiry: Nature, Society, and Method. Oxford: Blackwell, p. 1-22.

MOORE, Adam. (2008) Rethinking scale as a geographical category: from analysis to practice. Progress in Human Geography, v. 32, n. 2, pp. 203-225.

PECK, Jamie. (2002) Political Economies of Scale: Fast Policy, Interscalar Relations, and Neoliberal Workfare. Economic Geography, v. 78, n. 3, pp. 331-360.

SAARINEN, Thomas. (1969) Perception of environment. AAG: Washington.

SEWELL JR, William Hamilton. (1999) The Concept(s) of Culture. In: BONNEL, Victoria; HUNT, Lynn (eds): Beyond the Cultural Turn: new directions in the study of society and culture. University of California Press. p. $35-61$.

SHEPPARD, Eric. (2002) The spaces and times of globalization: Place, scale, networks, and positionality. Economic Geography, v. 78, n. 3, pp. 307-30.

SMITH, Neil. (1987) Dangers of the empirical turn: Some comments on the CURS initiative. Antipode, v. 19 , pp. $59-68$. 
SMITH, Neil. (1988 [1984]) Desenvolvimento desigual - Natureza, Capital e a produção de espaço. Rio de Janeiro: Bertrand Brasil.

SMITH, Neil. (1993) Homeless / global: scaling places. In: BIRD, John et al. (org.) (1993): Mapping the futures: Local cultures, global change. Londres e Nova York: Routledge.

SOUZA, Marcelo Lopes de. (2002) Mudar a cidade. Rio de Janeiro: Bertrand Brasil.

SOUZA, Marcelo Lopes de. (2006) A Prisão e a Ágora. Rio de Janeiro: Bertrand Brasil.

SOUZA, Marcelo Lopes de. (2010) Com o Estado, apesar do Estado, contra o Estado: os movimentos urbanos e suas práticas espaciais, entre a luta institucional e a ação direta. Revista Cidades - Formas Espaciais e Política(s) Urbana(s), v. 7, n. 11, pp. 13-48.

SOUZA, Marcelo Lopes de. (2013) Os conceitos fundamentais da pesquisa sócio-espacial. Rio de Janeiro: Bertrand Brasil.

SWYNGEDOUW, Erik. (1997a) Excluding the other: the production of scale and scaled politics. In: LEE, Roger; WILLS, Jane (ed.) (1997): Geographies of economies. Londres: Arnold, p. 167-176.

SWYNGEDOUW, Erik. (1997b) Neither global or local: "glocalisation" and the politics of scale. In COA, Kevin (ed.): Spaces of Globalisation: Reasserting the Power of the Local. New York: Guilford, pp. 138166.

SWYNGEDOUW, Erik. (2000) Authoritarian governance, power, and the politics of rescaling. Env \& Plan D, v. 18, n. 1, pp. 63-76.

SWYNGEDOUW, Erik. (2003) Urban political ecology, justice and the politics of scale. Antipode, v. 35, n. 5, pp. 898-918.

SWYNGEDOUW, Erik. (2004) Scaled geographies: Nature, place, and the politics of scale. In: SHEPPARD, E. McMASTER, R. (orgs.): Scale and Geographic Inquiry. Oxford: Blackwell, p. 129-153.

TAYLOR, Peter. (1981) Geographical Scales within the World-Economy Approach. Review (Fernand Braudel Center), v. 5, n. 1, pp. 3-11.

TAYLOR, Peter. (1982) A Materialist Framework for Political Geography. Transactions of the IBG, v. 7, n. 1, pp. 15-34.

TAYLOR, Peter. (1987) The paradox of scale in Marx's politics. Antipode, v. 19, n. 3. pp. 287-306.

THRIFT, Nigel. (2005) Torsten Hägerstrand and social theory. Progress in Human Geography, v. 29, pp. 337-340.

TUAN, Yi-Fu. (1980) Topofilia: um estudo da percepção, atitudes e valores do meio ambiente. São Paulo: Difel.

TUAN, Yi-Fu. (1983) Espaço e lugar: a perspectiva da experiência. São Paulo: Difel.

UTSUMI, A.G; GALO, M.L.B.T; TACHIBANA, V.M. (2015). Mapeamento de cianobactérias por meio da fluorescência da ficocianina e de análise geoestatística. Revista Brasileira de Engenharia Agrícola e Ambiental, Campina Grande, v.19, n.3, p. 273279. 